\title{
CORRESPONDENCE
}

\section{Out of plane approach to erector spinae plane block}

\author{
Poonam Darswal, MD, Divesh Arora, MD
}

Department of Anesthesiology Asian Institute of Medical Sciences Faridabad, Haryana, India

Correspondence: Dr Poonam Darswal, A-2224, Ground Floor, Greenfield Colony, Faridabad, India.

Phone: 9650399299; E-mail: poonam.darswal@gmail.com

Citation: Darswal P, Arora D. Out of plane approach to erector spinae plane block. Anaesth. pain \& intensive care 2020;24(3):366-367.

Received: 4 June 2020; Reviewed: 5 June 2020; Accepted; 7 June 2020

We were interested in applying the appealingly safer yet equally effective alternative suggested to thoracic paravertebral block - the erector spinae plane (ESP) block by Forereo ${ }^{1}$ to our clinical practice. ESP block is being used as an effective analgesic technique in abdominal and thoracic procedures like videoassisted thoracoscopic surgery (VATS) and bariatric surgeries. ${ }^{2,3}$ It is a very safe and effective analgesic technique with minimal potential for major complications. ESP block proved to be effective for analgesia in breast surgeries as well.

The only problem, we repeatedly encountered was the difficult target approach via in-plane approach under general anesthesia (GA) in the lateral decubitus position. It was not only difficult to steer the needle in this acute trajectory keeping the needle tip in view all the time, it also consumed much time. After detailed survey of available data, we decided to adopt the out-of-plane (OOP) approach recommended for the paravertebral block to perform the ESP block. ${ }^{4}$ After a written informed consent, four cases of modified radical mastectomy, ASA I/II, were selected to test the potential of this approach. Inj. ropivacaine $0.375 \% 20 \mathrm{ml}$ without an adjuvant was injected at a single level in all the cases. After induction of GA, the patients were positioned in the lateral decubitus position keeping the operative site up. Target for drug deposition was fixed at 5th transverse process (T5) which was marked counting downwards from C7 or upwards from T7. Sonoscan ${ }^{\circledR}$ was started 5 to $6 \mathrm{~cm}$ lateral to midline in parasagittal plane bringing rounded ribs in view first and

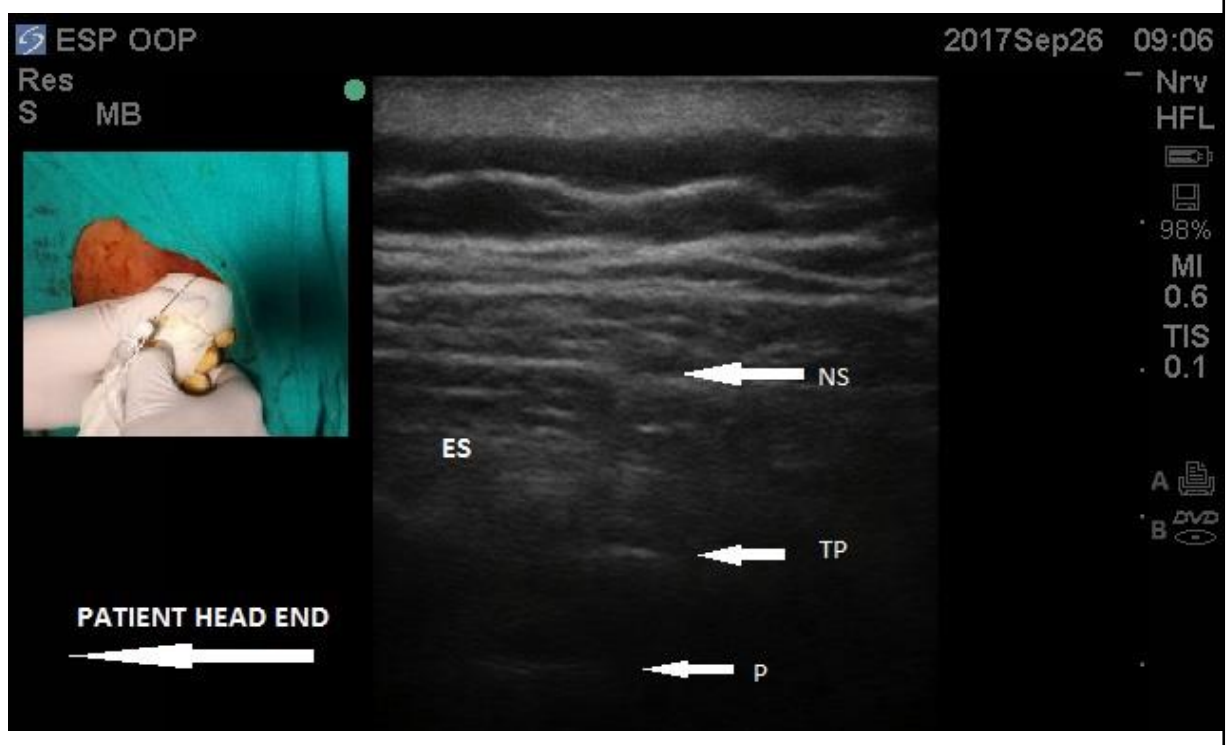

Picture 1: Performing the ESP block in OOP approach in lateral decubitus position. The transducer is kept in parasagital position with the pointer towards the patients head end. The desired transverse process (TP) is positioned in center of the scan window. The needle is introduced out of plane casting a perpendicular needle shadow (NS) to the TP. Pleura $(P)$ is seen at a deeper level than the TP and has characteristic shimmering appearance. Erector spinae (ES) muscle is seen covering the transverse processes. 
progressed medially till the tip of $\mathrm{T} 5$ transverse process was clearly visible and positioned in the center of the scan window. Keeping the desired transverse process (T5) in view, the bone was contacted out-ofplane using $22 \mathrm{G}$ blunt tip Sonoplex ${ }^{\circledR}$ needle from the lateral side of the probe (Picture 1). A gentle needle withdrawal let us deposit the drug effortlessly in the target area lifting the erector spinae muscle off the transverse processes (Picture 2). As more of the drug was injected, a bilateral transverse spreading anechoic shadow indicating interfacial spread was documented in all the cases. This approach dramatically decreased the time required to perform the block. Furthermore, we think that the need for operator expertise required for OOP approach is far less than that required in the in-plane approach.

The OOP ESP block provided excellent post-operative analgesia without any significant side effect. All the four patients had excellent satisfaction scores averaging $8 / 10$ on VAS, with an average analgesia duration of 12-18 hours. We hope this novel approach to ESP block can be used in many other clinical settings including surgical and non-surgical patients.

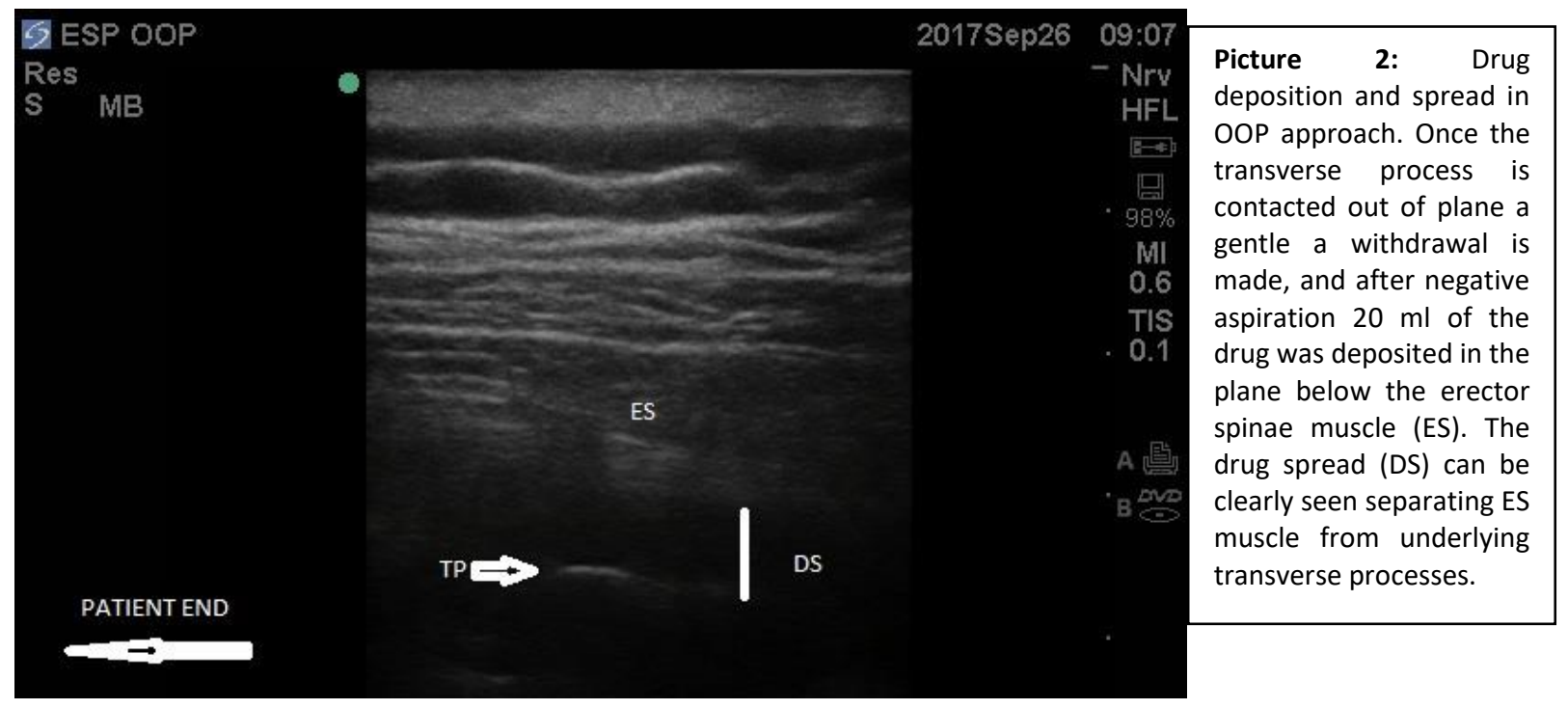

\section{References}

1. Forero M, Adhikary SD, Lopez H, Tsui C, Chin KJ. The erector spinae plane block: a novel analgesic technique in thoracic neuropathic pain. Reg Anesth Pain Med. 2016;41:621-627. [PubMed] DOI: 10.1097/AAP.0000000000000451

2. Chin KJ, Malhas L, Perlas A. The erector spinae plane block provides visceral abdominal analgesia in bariatric surgery: A report of 3 cases. Reg Anesth Pain Med.
2017;42:372-376.

[PubMed]

DOI: 10.1097/AAP.0000000000000581

3. Scimia P, Basso Ricci E, Droghetti A, Fusco P. The ultrasound-guided continuous erector spinae plane block for postoperative analgesia in video-assisted thoracoscopic lobectomy. Reg Anesth Pain Med. 2017 Jul/Aug;42(4):537. [PubMed] DOI: 10.1097/AAP.0000000000000616

4. Vandepitte C, Pintaric TS, Gautier PE. Thoracic Paravertebral Block. Landmark based ultrasound guided ultrasound block. NYSORA. [Accessed 27 September 2017]. 